CARDIOVASCULAR MEDICINE

\title{
Are the cardiac effects of anabolic steroid abuse in strength athletes reversible?
}

\author{
A Urhausen, T Albers, W Kindermann
}

Heart 2004;90:496-501. doi: 10.1136/hrt.2003.015719

See end of article for authors' affiliations

a....................

Correspondence to:

Dr Urhausen Axel, Institute of Sports and Preventive

Medicine, University of

Saarland, 66041

Saarbruecken, Germany;

a.urhausen@rz.uni-sb.de

Accepted

2 September 2003

\begin{abstract}
Objective: To investigate the reversibility of adverse cardiovascular effects after chronic abuse of anabolic androgenic steroids (AAS) in athletes.

Methods: Doppler echocardiography and cycle ergometry including measurements of blood pressure at rest and during exercise were undertaken in 32 bodybuilders or powerlifters, including 15 athletes who had not been taking AAS for at least 12 months (ex-users) and 17 currently abusing AAS (users), as well as in 15 anabolic-free weightlifters.

Results: Systolic blood pressure was higher in users (mean (SD) 140 (10) mm Hg) than in ex-users (130 (5) $\mathrm{mm} \mathrm{Hg})(\mathrm{p}<0.05)$ or weightlifters $(125(10) \mathrm{mm} \mathrm{Hg} ; \mathrm{p}<0.001)$. Left ventricular muscle mass related to fat-free body mass and the ratio of mean left ventricular wall thickness to internal diameter were not significantly higher in users $(3.32(0.48) \mathrm{g} / \mathrm{kg}$ and $42.1(4.4) \%)$ than in ex-users $(3.16(0.53) \mathrm{g} / \mathrm{kg}$ and $40.3(3.8) \%)$, but were lower in weightlifters $(2.43(0.26) \mathrm{g} / \mathrm{kg}$ and $36.5(4.0) \% ; \mathrm{p}<0.001)$. Left ventricular wall thickness related to fat-free body mass was also lower in weightlifters, but did not differ between users and ex-users. Left ventricular wall thickness was correlated with a point score estimating AAS abuse in users $(r=0.49, p<0.05)$. In all groups, systolic left ventricular function was within the normal range. The maximum late transmitral Doppler flow velocity (Amax) was higher in users (6) $(12) \mathrm{cm} / \mathrm{s})$ and ex-users $(60(12) \mathrm{cm} / \mathrm{s})$ than in weightlifters $(50(9) \mathrm{cm} / \mathrm{s} ; \mathrm{p}<0.05$ and $\mathrm{p}=0.054)$.

Conclusions: Several years after discontinuation of anabolic steroid abuse, strength athletes still show a slight concentric left ventricular hypertrophy in comparison with AAS-free strength athletes.
\end{abstract}

A nabolic androgenic steroids (AAS) have been used by strength athletes for almost five decades in order to improve performance by increasing muscle mass and strength. Abuse of these drugs also involves many athletes practising leisure time sports who want to enhance their physical appearance and who act upon recommendations given by training colleagues or the underground literature when choosing the preparations and fixing the dosages.

Among the numerous documented toxic and hormonal effects of AAS, attention has been focused especially on the cardiovascular effects during recent years. ${ }^{1}$ Increases in blood pressure and peripheral arterial resistance are known from experimental studies, ${ }^{2}{ }^{3}$ but there are also effects on the heart muscle, primarily left ventricular hypertrophy with restricted diastolic function. ${ }^{4-6}$ Severe cardiac complications such as cardiac insufficiency, ventricular fibrillation, ventricular thromboses, myocardial infarction, or sudden cardiac death in individual strength athletes with acute AAS abuse have also been reported. ${ }^{1{ }^{78}}$ In almost all studies, acute side effects were examined only during AAS intake or within weeks to a few months of their discontinuance. However, the extent to which these effects are reversible after discontinuing intake of these agents and the degree to which they leave permanent impairment are still controversial matters. In former Finnish world class powerlifters suspected of AAS intake during their sports career, a 4.6 times higher mortality was reported compared with a control group of 1094 men. ${ }^{9}$ However, the very small number of deaths (only four cardiovascular deaths in the 62 athletes) restricted the validity of this study in determining whether there was a higher cardiac risk in AAS users.

In the present study, we have examined for the first time whether cardiovascular changes are detectable one to several years after discontinuing AAS abuse in male former users.
This group was compared with current AAS users and with highly trained anabolic-free strength athletes.

\section{METHODS}

Thirty two male bodybuilders and 15 male weightlifters from the national weightlifting team, who were not taking AAS, participated on a voluntary basis (table 1). All subjects gave written informed consent. Anonymity was expressly guaranteed. The study was approved by the review committee of the German National Institute of Sports Sciences.

Fifteen athletes (ex-users) had discontinued their self administered use of AAS at least one year before the study (mean 43 months, median 24 months, minimum 12 months, maximum 10 years); their mean self reported dose had amounted to $720 \mathrm{mg} /$ week for 26 weeks a year over nine years. Seventeen athletes (users) were current users of AAS (examined while "on treatment") at a mean dose of $1030 \mathrm{mg} /$ week (median $750 \mathrm{mg}$ ) for 33 weeks a year over eight years.

The AAS reported to be given by intramuscular injections were boldenone, drostanolone, formebolone, metenolone, nandrolone, stanozolol, esters of testosterone, and trenbolone. The substances taken orally included 4-dehydrochlormethyltestosterone, fluoxymesterone, mesterolone, metenolone, metandienone, oxandrolone, oxymetholone, and stanozolol. All except two ex-users used combinations of both oral and injectable substances. Five ex-users and six users had sporadic experiences ( $<1$ year; 2-16 IU daily) with growth hormone, nine ex-users and 15 users took clenbuterol (60-400 $\mu \mathrm{g}$ daily; therapeutic dosage $20 \mu \mathrm{g})$, while nine ex-users and 14 users took antioestrogens. One ex-user took cocaine sporadically (three times a months for the previous four years), two users had taken cocaine once in the past. 


\begin{tabular}{|c|c|c|c|}
\hline & Ex-users $(n=15)$ & Users $(n=17)$ & Weightlifters $(n=15)$ \\
\hline $\begin{array}{l}\text { Age (years) } \\
\text { Height }(\mathrm{cm}) \\
\text { Body mass }(\mathrm{kg}) \\
\text { Fat-free body mass }(\mathrm{kg}) \\
\text { Body surface area }\left(\mathrm{m}^{2}\right)\end{array}$ & $\begin{array}{l}38.0(7.0) \\
176.0(6.0) \\
89.5(10.0) \\
74.0(9.0) \\
2.06(0.13)\end{array}$ & $\begin{array}{l}30.5(5.0)^{* *} \\
176.5(8.0) \\
96.0(10.0) \\
84.0(8.0)^{*} \\
2.12(0.16)\end{array}$ & $\begin{array}{l}28.0(4.5) \mathrm{tt \dagger} \\
176.0(5.5) \\
103.5(24.0) \\
84.0(14.0) \dagger \\
2.18(0.25)\end{array}$ \\
\hline \multicolumn{4}{|c|}{$\begin{array}{l}\text { Values are mean (SD). } \\
\text { Users } v \text { ex-users: }{ }^{*} p<0.05,{ }^{* *} p<0.01 \\
\text { Ex-users } v \text { weightliffers: } t p<0.05,+t+p<0.001\end{array}$} \\
\hline
\end{tabular}

The classification into ex-users, users, and anabolic-free weightlifters was strengthened by additional measurements of luteinising and follicle stimulating hormones, showing clearly depressed blood concentrations in all users, while all ex-users and the nine weightlifters measured had normal values. Per year each weightlifter had approximately nine doping tests out of competition, and three to four tests during competition. All were negative.

\section{AAS score}

To estimate the extent of AAS abuse, a point score was established. One to four points were given in each of the categories "years of administration" (2.5 to 4.0, 5.0 to 6.0, 6.5 to 10.0 , and $>10$ years), "weeks of AAS use per year" $(<20$, 21 to 30,31 to 37 , and $>38$ weeks), and "weekly dosage in $\mathrm{mg}^{\prime \prime}(<500,550$ to 750,800 to 1250 , and $>1250 \mathrm{mg})$. The limits were chosen in order to include 6-10 athletes in each of the categories; if other anabolic substances such as growth hormone and clenbuterol were used, an additional point was accorded. The maximum point score available was therefore 14 and the minimum 3. The mean (SD) AAS score of users was not significantly higher than that of ex-users, at 9.2 (2.7) v 7.8 (3.2).

Ex-users had been training for 14.0 (4.5) years for 6.0 (2.0) hours a week, users for 11.0 (5.0) years for 6.0 (1.0) hours a week, and weightlifters for 13.8 (3.6) years for 11.7 (1.5) hours a week (NS). In addition to the bodybuilding, six exusers and one user had also been active in powerlifting. Maximum self reported one-repetition squat results were 169 (36) $\mathrm{kg}$ in ex-users, 203 (26) $\mathrm{kg}$ in users, and 264 (21) kg in weightlifters (all differences $\mathrm{p}<0.001$ ). In addition to the strength training, ex-users and users did approximately two hours of low intensity endurance training ("fat burning") a week.

\section{Anthropometric measurements}

Body height and mass were measured and the body surface area estimated from a nomogram. The percentage of body fat and the resulting fat-free body mass were calculated from 10 skinfold measurements using the calliper method. ${ }^{10}$

\section{Ergometry}

All subjects undertook an incremental graded exercise test on an electrically braked cycle ergometer in the sitting position, increasing by $50 \mathrm{~W}$ every three minutes until volitional exhaustion. The test included 12 channel ECG recordings and blood pressure measurements according to Riva-Rocci, using a cuff specially adapted to the enlarged upper arm girth at rest (at least two measurements on both arms after 10 minutes in the supine position) and during exercise. Peak oxygen uptake was calculated from the maximum power output by internal regression analysis.

\section{Doppler echocardiography}

The echocardiographic recordings and measurements were made according to the American Society of Echocardiography in the supine left lateral position by the same experienced investigator, who was blinded to AAS use and to the results of the physical examination $(2.5 \mathrm{MHz}$ transducer, System Five, GE, Horten, Norway). Left ventricular muscle mass was calculated according to Devereux and colleagues, ${ }^{11}$ along with the hypertrophic index (interventricular septum plus posterior wall thickness divided by the internal diameter). Systolic function was determined by measurements of fractional shortening (end diastolic left ventricular internal diameter minus end systolic diameter divided by end diastolic diameter). Diastolic function was evaluated by Doppler echocardiography based on the maximum transmitral flow velocities during the early (Emax) and late (Amax) diastolic filling phase, measured at the tips of the mitral leaflets in the four chamber view.

\section{Statistics}

Data are expressed as mean (SD). The level of significance was set at $\mathrm{p}<0.05$. Differences between the groups were calculated using analysis of variance with post hoc comparisons (Scheffé test) if the overall probability value was $\mathrm{p}<0.05$. Relations between selected measures were calculated by Spearman rank correlation.

\section{RESULTS}

\section{Anthropometric data and ergometry}

Ex-users were older than users and weightlifters. Fat-free body mass was higher in users than in ex-users (table 1). Performance data did not differ between users and ex-users (table 2). In relation to body mass, maximum performance of weightlifters was less than that of ex-users or users, with the maximum heart rate indicating exhaustion at a lower level in the weightlifter group.

\section{Electrocardiography}

One user showed constant ST segment depressions of $0.2 \mathrm{mV}$ in leads II, III, aVF, and V4-V6 at rest and during exercise. After discontinuing the intake of anabolic drugs, these ECG changes were no longer present six months later, while the Doppler echocardiographic measurements remained unchanged (interventricular septum $13 \mathrm{~mm}$, E/Amax 1.0). In all other subjects the ECG at rest and during exercise showed no peculiarities.

\section{Blood pressure}

Five users, two ex-users, and one weightlifter showed high borderline blood pressure values at rest (defined as systolic values between $140-160 \mathrm{~mm} \mathrm{Hg}$ and diastolic values between $95-110 \mathrm{~mm} \mathrm{Hg}$ ), which returned to normal at $100 \mathrm{~W}$ during exercise, with the exception of two users with borderline diastolic blood pressure values of 100 and $105 \mathrm{~mm} \mathrm{Hg}$, respectively. The systolic blood pressure of users at rest and at $100 \mathrm{~W}$ exercise was higher than that of the weightlifters (table 2). 
Table 2 Ergometric data and arterial blood pressure

\begin{tabular}{|c|c|c|c|}
\hline & Ex-users $(n=15)$ & Users $(n=16)$ & Weightlifters $(n=15)$ \\
\hline $\begin{array}{l}\text { Max performance }(\mathrm{W} / \mathrm{kg}) \\
\text { Max heart rate }(\text { beats } / \mathrm{min}) \\
\left.\dot{V}_{2} \text { peak (ml/min. } \mathrm{kg}\right) \\
\mathrm{PWC} 150(\mathrm{~W} / \mathrm{kg}) \\
\text { Systolic BP (rest) }(\mathrm{mm} \mathrm{Hg}) \\
\text { Diastolic BP (rest) }(\mathrm{mm} \mathrm{Hg}) \\
\text { Systolic BP }(100 \mathrm{~W})(\mathrm{mm} \mathrm{Hg})\end{array}$ & $\begin{array}{l}2.83(0.48) \\
176(12) \\
39.0(5.0) \\
2.02(0.36) \\
130(5) \\
85(5) \\
155(15)\end{array}$ & $\begin{array}{l}2.70(0.29) \\
177(10) \\
37.0(3.5) \\
1.99(0.25) \\
140(10)^{*} \\
85(10) \\
160(15)\end{array}$ & $\begin{array}{l}2.28(0.51) \dagger+\ddagger \\
165(11) \dagger \ddagger \\
32.0(7.0) \\
1.82(0.23) \\
125(10) \ddagger \ddagger \ddagger \\
80(10) \\
145(15) \ddagger\end{array}$ \\
\hline \multicolumn{4}{|c|}{ 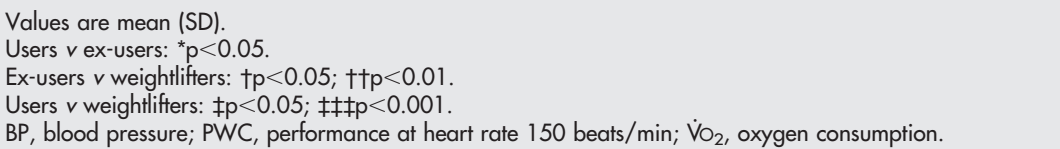 } \\
\hline
\end{tabular}

\section{Echocardiography}

The echocardiography data are shown in table 3.

Left ventricular muscle mass was clearly lower in weightlifters than in ex-users and users. There were no differences between users and ex-users with regard to fatfree body mass. A significant correlation between fat-free body mass and left ventricular muscle mass was found in users and ex-users $(r=0.692, \mathrm{p}<0.001 ; \mathrm{n}=32)$.

The end diastolic left ventricular internal diameter (EDD) did not show any absolute or body surface area related differences between ex-users and users; related to the fat-free body mass it is slightly higher in ex-users than in users and weightlifters.

Left ventricular wall thicknesses and hypertrophic index (fig 1) were significantly lower in weightlifters, with no differences between ex-users and users in wall thicknesses when related to body dimensions. Two ex-users, seven users, and none of the weightlifters had a left ventricular wall thickness of $13 \mathrm{~mm}$ or more. The mean left ventricular wall thickness correlated significantly with AAS score in users and ex-users (fig 2). Two ex-users and four users, but none of the weightlifters, had a hypertrophic index of $45 \%$ or higher.

Fractional shortening values were not significantly different between the groups (table 4). Emax was lower in ex-users than in users and weightlifters. Amax was significantly lower in weightlifters than in users, and there was a trend for it to be lower in weightlifters than in ex-users ( $p=0.054)$. E/Amax was lower in ex-users, and possibly in users $(p=0.057)$, than in weightlifters (table 4$)$. With age as a covariate in the analysis of variance, Amax was significantly lower in weightlifters than in ex-users and users $(p<0.05$ for both), while E/Amax showed only a trend to differences between the groups $(\mathrm{p}=0.093)$.

\section{DISCUSSION}

This is the first time that a relatively large number of strength athletes has undergone a cardiological examination at least one year (mean 43 months) after discontinuation of their previous AAS abuse and been compared with current users. In an earlier study, ${ }^{12}$ the AAS intake was discontinued for several months only. In our subjects, AAS usage considerably exceeded the clinical dose, and the interindividual intake methods varied substantially. However, there was no significant difference in AAS dosage between ex-users and users. National team weight lifters were used as a control group for highly trained AAS-free strength athletes.

The ergometric performance in our subjects was within the normal range for untrained persons of the same age, even when considering the moderate exhaustion of the weightlifters (with a lower maximum heart rate towards the end of exercise). The typical training in bodybuilding and weightlifting, including the moderate endurance training on a cycle ergometer done by most of the athletes, does not result in significant increases in cycle ergometry performance.

The reversible ST segment changes observed in one user after discontinuation of AAS use could be related to AAS intake. Only individual case descriptions of ECG changes with AAS abuse are found in published reports. ${ }^{17}$ In a

Table 3 Echocardiographic data on the left ventricle

\begin{tabular}{|c|c|c|c|}
\hline & Ex-users $(n=15)$ & Users $(n=17)$ & Weightlifters $(n=15)$ \\
\hline $\operatorname{LVMM}(\mathrm{g})$ & $232 \pm 42$ & $281(54)^{*}$ & 204 (44)㧊 \\
\hline LVMM per unit BSA $\left(\mathrm{g} / \mathrm{m}^{2}\right)$ & $112(17)$ & $132(23)^{*}$ & $93(12) \dagger \pm \ddagger \ddagger$ \\
\hline LVMM per unit FFM $(\mathrm{g} / \mathrm{kg})$ & $3.16(0.53)$ & $3.32(0.48)$ & 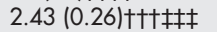 \\
\hline EDD $(\mathrm{mm})$ & $54.0(5.0)$ & $56.5(3.5)$ & $54.0(4.0)$ \\
\hline EDD per unit BSA $\left(\mathrm{mm} / \mathrm{m}^{2}\right)$ & $26.0(2.0)$ & $26.5(2.0)$ & $25.0(2.0) \ddagger$ \\
\hline EDD per unit FFM $(\mathrm{mm} / \mathrm{kg})$ & $0.74(0.08)$ & $0.67(0.05)^{*}$ & $0.66(0.08)+\dagger$ \\
\hline $\mathrm{ESD}(\mathrm{mm})$ & $35.0(4.5)$ & $38.5(2.5)^{*}$ & $36.0(3.5)$ \\
\hline IVS (mm) & $11.5(1.2)$ & $12.3(1.4)$ & 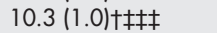 \\
\hline IVS per unit BSA $\left(\mathrm{mm} / \mathrm{m}^{2}\right)$ & $5.6(0.6)$ & $5.8(0.7)$ & 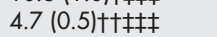 \\
\hline IVS per unit FFM $(\mathrm{mm} / \mathrm{kg})$ & $0.16(0.02)$ & $0.15(0.02)$ & $0.13(0.02) \dagger \dagger † \ddagger$ \\
\hline LVPW (mm) & $10.2(0.8)$ & $11.4(1.3)^{*}$ & $9.4(1.5) \neq \ddagger \ddagger$ \\
\hline LVPW per unit BSA $\left(\mathrm{mm} / \mathrm{m}^{2}\right)$ & $5.0(0.5)$ & $5.4(0.6)$ & 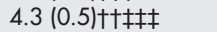 \\
\hline LVPW per unit FFM $(\mathrm{mm} / \mathrm{kg})$ & $0.14(0.02)$ & $0.14(0.01)$ & 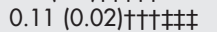 \\
\hline
\end{tabular}

Values are mean (SD).

Users $v$ ex-users: * $\mathrm{p}<0.05$.

Ex-users $v$ weightlifters: $\uparrow \mathrm{p}<0.05 ; \uparrow+p<0.01 ; \uparrow+\uparrow p<0.001$.

Users $v$ weightlifters: $\neq p<0.05$; $\neq \ddagger \neq p<0.001$.

BSA, body surface area; EDD, end diastolic internal diameter; ESD, end systolic internal diameter; FFM, fat-free body mass; IVS, interventricular septum; LVMM, left ventricular muscle mass; LVPW, left ventricular posterior wall. 


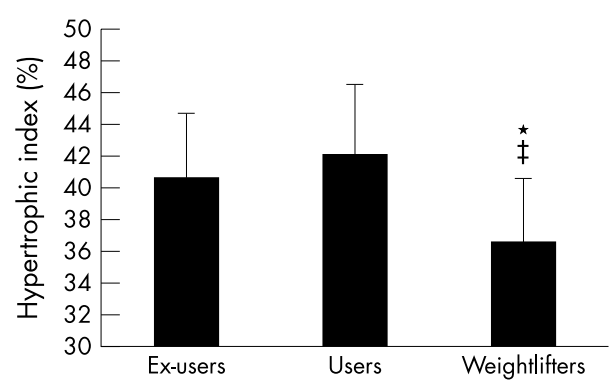

Figure 1 Hypertrophic index (interventricular septum plus left ventricular posterior wall thickness divided by internal diameter). Values are means, error bars $=S D$. Ex-users $v$ weightlifters: ${ }^{*} p<0.05$; users $v$ weightlifters: $\ddagger \mathrm{p}<0.01$.

previous investigation, ECG abnormalities could not be established. ${ }^{6}$

Our results suggest that the increases in blood pressure with AAS use are rather small and transient. Increased blood pressure values ${ }^{213}$ or a reduced fall in blood pressure during sleep $^{14}$ have been described with AAS use, but not in all studies. ${ }^{6}$ These discrepancies probably reflect different preparations, dosages, and intake cycles. Lenders and colleagues reported that five months after discontinuing AAS intake, systolic blood pressure remained higher by $6 \mathrm{~mm} \mathrm{Hg}$ at rest compared with an anabolic-free control group. ${ }^{3}$ In animal experiments an increase in peripheral resistance was still detectable six weeks after AAS use. ${ }^{15}$

Particularly in athletes it is important to consider differences of fat-free body mass when comparing echocardiographic measures. The left ventricular muscle mass and wall thicknesses values of ex-users relative to fat-free body mass were similar to those of users. The weightlifters group, however, showed significantly lower values. This suggests not only a disproportionate increase in left ventricular muscle mass with AAS, but also residual left ventricular hypertrophy more than one year after discontinuing AAS intake. Increases in left ventricular muscle mass with AAS are well documented in strength athletes ${ }^{4121316}$ (with case reports of typical hypertrophic cardiomyopathy ${ }^{17}$ ) as well as in animals, ${ }^{15}{ }^{18}$ where an increased protein synthesis has been shown. ${ }^{19}$ Androgen receptors are known to be present in human myocardial tissue. ${ }^{20}$ Intracellular oedema and mitochondrial swelling in myocytes ${ }^{21}$ could also play a role in hypertrophy. In case reports, reversibility of significantly increased left ventricular muscle mass has been described after discontinuation of AAS. ${ }^{12}$ Other studies suggest that, relative to body dimensions, AAS have a long lasting disproportionately hypertrophic effect on the myocardium, as former users still show an increase in left ventricular muscle mass four to six weeks $^{16}$ or nine months ${ }^{4}$ after discontinuing these agents.

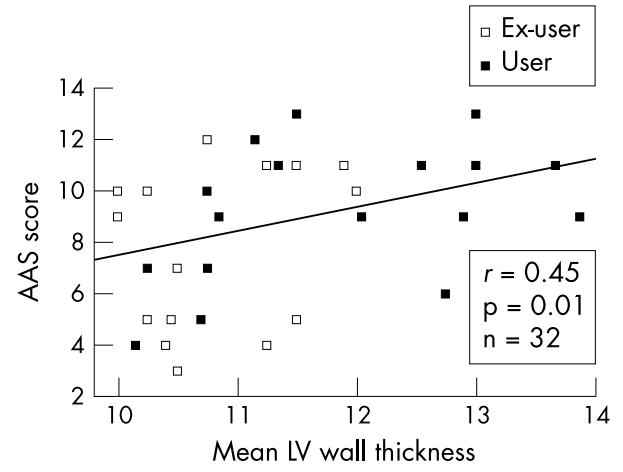

Figure 2 Linear correlation of the mean left ventricular wall thickness (interventricular septum plus left ventricular posterior wall thickness/2) with AAS score.

Our results suggest that this effect is maintained for an even longer time.

The extent to which increased left ventricular muscle mass caused by AAS abuse represents a long term risk for cardiac complications is controversial. The correlation between left ventricular muscle mass and cardiovascular mortality that is suggested by epidemiological evidence ${ }^{22}$ may be transferable to athletes only with caution. An increased left ventricular muscle mass of up to $170 \mathrm{~g} / \mathrm{m}^{2}$ can be found in healthy highly endurance trained athletes. ${ }^{23}{ }^{24}$ Left ventricular wall thicknesses of 13-16 mm have been described in individual athletes with large body dimensions involved in combined strength-endurance sports, such as rowing. ${ }^{23}{ }^{24}$ In contrast to those athlete's hearts, clinical hypertrophic cardiomyopathy-even with endurance training-is always associated with a rather small internal left ventricular diameter of less than $48-50 \mathrm{~mm}^{25}$

The higher ratio of wall thickness to internal diameter in ex-users and users underlines the assumption that there is a slight degree of concentric left ventricular hypertrophy in AAS users, even more than one year after discontinuing the intake of these agents. Today, most investigators agree that strength training without AAS intake does not induce concentric left ventricular hypertrophy. ${ }^{24}{ }^{26}$ Previous echocardiographic data in athletes taking AAS are less conclusive. Some investigators describe significant wall thickening compared with steroid-free strength athletes, ${ }^{42}{ }^{27}$ with regression after eight weeks off treatment ${ }^{12}$ or no change after nine weeks. ${ }^{4}$ Other studies, however, report only nonsignificant differences ${ }^{14}$ or no differences ${ }^{28} 29$ between strength athletes using or not using AAS.

Ex-users lie between the non-users (weightlifters) and users with respect to left ventricular muscle mass, wall thicknesses, and hypertrophic index values. This could

Table 4 Doppler echocardiographic data on systolic and diastolic left ventricular function and heart rate during examination

\begin{tabular}{|c|c|c|c|}
\hline & Ex-users $(n=15)$ & Users $(n=17)$ & Weightlifters $(n=15)$ \\
\hline $\begin{array}{l}\text { Fractional shortening (\%) } \\
\text { Emax }(\mathrm{cm} / \mathrm{s}) \\
\operatorname{Amax}(\mathrm{cm} / \mathrm{s}) \\
E / A m a x \\
\text { Heart rate (beats } / \mathrm{min})\end{array}$ & $\begin{array}{l}35.7(5.8) \\
72(13) \\
60(12) \\
1.24(0.31) \\
73(14)\end{array}$ & $\begin{array}{l}31.7(3.7) \\
85(13)^{*} \\
61(12) \\
1.44(0.32) \\
73(12)\end{array}$ & $\begin{array}{l}33.1(4.8) \\
85(14) \dagger \\
50(9) \ddagger \\
1.76(0.45) \dagger \dagger \\
71(11)\end{array}$ \\
\hline \multicolumn{4}{|c|}{$\begin{array}{l}\text { Values are mean (SD). } \\
\text { Users } v \text { ex-users: }{ }^{*} p<0.05 \text {. } \\
\text { Ex-users } v \text { weightlifters: } t p<0.05,+t p<0.01 \\
\text { Users } v \text { weightlifters: } \neq p<0.05 \text {. } \\
\text { Amax, maximum late transmitral flow velocity; Emax, maximum early transmitral flow velocity; E/Amax, ratio of } \\
\text { maximum early to late transmitral flow velocity. }\end{array}$} \\
\hline
\end{tabular}


suggest that the hypertrophic effect of AAS decreases over the years.

In our study, left ventricular systolic function in the users was still within the normal range, in agreement with other investigators' findings. ${ }^{421629}$ Nieminen and colleagues, ${ }^{7}$ however, described two serious cases in which AAS users presented with reduced fractional shortening values of $14 \%$ and $13 \%$, respectively. In the first of these cases, where a subsequent evaluation was made nine months after discontinuing AAS, this variable had almost returned to normal $(27 \%)$. An impairment of systolic left ventricular function in animals has been shown with AAS. ${ }^{18}$

Impairment of diastolic left ventricular function with AAS use ${ }^{4-6}$ is not unequivocal. ${ }^{14} 162729$ These discrepancies might be explained by different methods used to assess the diastolic function as well as by variations in the dose of AAS. In the present study there was a higher maximum late transmitral flow velocity and at least a tendency towards a lower E/Amax ratio in ex-users and users compared with weightlifters, which might suggest a relaxation disturbance. Fibrosis of the myocardium, as described in the case of anabolic abuse, ${ }^{30}$ could be responsible for this. The greater age of ex-users should be considered, because diastolic function is known to decline with age; however, the differences found were greater than could be expected from a difference in age of 10 years (from data of Wilkenshoff and colleagues, ${ }^{31}$ there is a decrease of $4-5 \%$ between the ages of 20-29 years and 30-39 years) and persisted after correction for age. The E/Amax ratio on Doppler echocardiography depends on many other factors, especially preload and afterload conditions, and this makes it difficult to draw definitive conclusions about diastolic left ventricular function from conventional transmitral echocardiography.

\section{Limitations}

Our study has several methodological limitations. First, it was based on cross sectional rather than longitudinal data. It does not seem reasonable, however, to suppose that strength athletes choosing to take anabolic drugs have different initial cardiac measurement results from AAS-free athletes. Age and body dimensions were not exactly the same in the three groups, which seems inevitable as former users of AAS who have taken the same quantity of drugs as current users must be somewhat older; however, when we related the echocardiographic results to body dimensions the hypertrophic index did not differ over a 10 year age period. A longitudinal study with human subjects would also give rise ethical problems.

Second, information about the intake of steroids was self reported, but it is hardly possible to assess this in an objective way. It seems unlikely that the small differences in AAS intake (AAS score was not significantly different between users and ex-users) could explain our results. The AAS can only attempt to approximate the relation between dose and effect, because the drugs differ in androgenic potency and bioavailability.

Finally, training related influences are also improbable as an explanation for the differences between the AAS users and weightlifters in our study. Previous echocardiographic data ${ }^{13}$ did not differ between bodybuilders and weightlifters. Earlier results in steroid-free bodybuilders with a hypertrophic index of $36-38 \%{ }^{4}{ }^{14}$ show the same value as the weightlifters in the present study. Also, training in bodybuilding is more endurance oriented, with more repetition, smaller weights, and shorter pauses than in weightlifting (and powerlifting), the latter involving fewer repetitions, heavier weights, and longer breaks between training sets. Thus the typical training of bodybuilders (both users and ex-users) would be expected to induce a more eccentric hypertrophy characterised by a greater increase in internal diameter than in wall thickness, in contrast to the more concentric left ventricular hypertrophy found in the present study.

\section{Conclusions}

Our results suggest that AAS-using strength athletes have a slight concentric left ventricular hypertrophy, with some indication of decreased diastolic function several years after ceasing AAS abuse, compared with steroid-free strength athletes.

\section{ACKNOWLEDGEMENTS}

This study was supported by grants of the Bundesinstitut für Sportwissenschaft, Bonn, Germany.

\section{Authors' affiliations}

A Urhausen, T Albers, W Kindermann, Institute of Sports and Preventive Medicine, University of Saarland Saarbruecken, Germany

\section{REFERENCES}

1 Sullivan ML, C, Martinez CM, Gennis P, et al. The cardiac toxicity of anabolic steroids. Prog Cardiovasc Dis 1998;41:1-15.

2 Freed DLJ, Banks AJ, Longson D, et al. Anabolic steroids in athletics: crossover double-blind trial on weightlifters. BMJ 1975;ii:471-3.

3 Lenders JW, De Macker PN, Vos JA, et al. Deleterious effects of anabolic steroids on serum lipoproteins, blood pressure and liver function in amateur body builders. Int J Sports Med 1988;9:19-23.

4 De Piccoli B, Giada F, Benettin A, et al. Anabolic steroid use in body builders: an echocardiographic study of left ventricle morphology and function. Int J Sports Med 1991;12:408-12.

5 Pearson AC, Schiff M, Mrosek D, et al. Left ventricular function in weightlifters. Am J Cardiol 1986;58:1254-9.

6 Urhausen A, Hölpes R, Kindermann W. One- and two-dimensional echocardiography in bodybuilders using anabolic steroids. Eur J Appl Physiol Occup Physiol 1989;58:633-40.

7 Nieminen MS, Rämö MP, Viitasalo $M$, et al. Serious cardiovascular side effects of large doses of anabolic steroids in weight lifters. Eur Heart $J$ 1996;17:1576-83.

8 Thiblin I, Lindquist $\mathrm{O}$, Rajs J. Cause and manner of death among users of anabolic androgenic steroids. J Forensic Sci 2000;45:16-23.

9 Pärssinen M, Kujala U, Vartiainen E, et al. Increased premature mortality of competitive powerliffers suspected to have used anabolic agents. Int J Sports Med 2000;21:225-7.

10 Parizkova J, Buzkova P. Relationship between skinfold thickness measured by Harpenden caliper and densitometric analysis of total body fat in men. Hum Biol 1971;43:16-21.

11 Devereux RB, Alonso DR, Lutas EM, et al. Echocardiographic assessment of left ventricular hypertrophy: comparison to necropsy findings. Am J Cardiol 1986;57:450-8.

12 Sachtleben TR, Berg KE, Elias A, et al. The effects of anabolic steroids on myocardial structure and cardiovascular fitness. Med Sci Sports Exerc 1993;25:1240-5.

13 Deligiannis A, Zahapoulou E, Mandroukas K. Echocardiographic study of cardiac dimension and function in weight lifters and body builders. J Sports Cardiol 1988;5:24-32.

14 Palatini P, Giada F, Garavelli G, et al. Cardiovascular effects of anabolic steroids in weight-trained subjects. J Clin Pharmacol 1996;36:1132-40.

15 Karhunen MK, Rämö MP, Kettunen R. Anabolic steroids alter the haemodynamic effects of endurance training and deconditioning in rats. Acta Physiol Scand 1988;133:291-306.

16 Di Bello V, Girogi D, Bianchi M, et al. Effects of anabolic-androgenic steroids on weight-lifters' myocardium: an ultrasonic videodensitometric study. Med Sci Sports Exerc 1999;31:514-21.

17 Luke JL, Farb A, Virmani R, et al. Sudden cardiac death during exercise in a weight lifter using anabolic-androgenic steroids: pathological and toxicological findings. J Forensic Sci 1990;35:1441-7.

18 Pesola MK. Reversibility of the haemodynamic effects of anabolic steroids in rats. Eur J Appl Physiol 1988;58:125-31.

19 Kinson GA, Layberry RA, Herbert B. Influences of anabolic androgens on cardiac growth and metabolism in the rat. Can J Physiol Pharmacol 1991;69:1698-704.

20 Marsh JD, Lehmann MH, Ritchie RH, et al. Androgen receptors mediate hypertrophy in cardiac myocytes. Circulation 1998;98:256-61.

21 Behrendt H, Boffin H. Myocardial cell lesions caused by anabolic hormone. Cell Tissue Res 1977;181:423-26.

22 Levy D, Garrison RJ, Savage DD, et al. Prognostic implications of echocardiographically determined left ventricular mass in the Framingham Heart Study. N Engl J Med 1990;322:1561-6.

23 Pelliccia A, Maron BJ, Spataro A, et al. The upper limit of physiologic cardiac hypertrophy in highly trained elite athletes. NEngl J Med 1991;324:295-301. 
24 Urhausen A Kindermann W. Sports-specific adaptions and differentiation of the athlete's heart. Sports Med 1999;28:237-44.

25 Dickhuth HH, Rocker K, Hipp A, et al. Echocardiographic findings in endurance athletes with hypertrophic non-obstructive cardiomyopathy (HNCM) compared to non-athletes with HNCM and to physiological hypertrophy (athlete's heart). Int J Sports Med 1994;15:273-7.

26 Pelliccia A, Spataro A, Caselli G, et al. Absence of left-ventricular wall thickening in athletes engaged in intense power training. Am J Cardiol 1993:72:1048-54.

27 Dickerman RD, Schaller F, Zachariah NY, et al. Left ventricular size and function in elite bodybuilders using anabolic steroids. Clin J Sport Med 1997;7:90-3
28 Salke RC, Rowland TW, Burke EJ. Left ventricular size and function in body builders using anabolic steroids. Med Sci Sports Exerc 1985;17:701-4.

29 Thompson PD, Sadaniantz A, Cullinane EM, et al. Left ventricular function is not impaired in weight-lifters who use anabolic steroids. J Am Coll Cardiol 1992:19:278-82.

30 Legros T, McConnel D, Murry T, et al. The effects of 17 alphamethyltestosterone on myocardial function in vitro. Med Sci Sports Exerc 2000;32:897-903.

31 Wilkenshoff UM, Hatle L, Sovany A, et al. Age-dependent changes in regional diastolic function evaluated by color Doppler myocardial imaging: a comparison with pulsed Doppler indexes of global function. J Am Soc Echocardiogr 2001;14:959-69.

\section{IMAGES IN CARDIOLOGY}

\section{Resolution of intracoronary thrombus with direct thrombin inhibition in a cocaine abuser}

A 38 year old black male was admitted with a 10 hour history of central chest pain. He was a cocaine abuser with intake within 24 hours of admission. He was a smoker but had no other identifiable risk factors for coronary disease. ECG showed anterolateral ST elevation with biphasic T waves (upper ECG). Cardiac enzymes were elevated with troponin I concentration of $81 \mathrm{U} / \mathrm{ml}$ (reference $<2 \mathrm{U} / \mathrm{ml}$ ) and creatine kinase $\mathrm{MB}$ concentration of $42 \mathrm{ng} / \mathrm{ml}$ (reference $<16.6 \mathrm{ng} / \mathrm{ml}$ ). Treatment with aspirin, unfractionated heparin, and nitrates was commenced and coronary angiography was scheduled. Angiography at 48 hours postadmission revealed a large thrombus in the proximal left anterior descending artery but otherwise normal arteries (middle row, left panel).

A diagnosis of cocaine induced coronary thrombosis was made. Atheromatous plaque rupture and thrombosis was considered but deemed less likely as coronary arteries were otherwise normal. Cocaine abuse is a recognised cause of coronary thrombosis, the pathogenic mechanisms being vasoconstriction, platelet activation, endothelial dysfunction, and impaired fibrinolysis.

Percutaneous intervention using distal embolisation protection was considered but dismissed as the risk of device induced embolisation was considered significant. Medical treatment was commenced with tirofiban and low molecular weight heparin. Repeat angiography 48 hours later showed no significant improvement (middle row, middle panel). Heparin and tirofiban were replaced with bivalirudin, a direct thrombin inhibitor (bolus $0.1 \mathrm{mg} / \mathrm{kg}$, followed by $0.25 \mathrm{mg} / \mathrm{kg} /$ hour) with the rationale that its unique ability to inhibit both fibrin bound and soluble thrombin, and the absence of effects on platelet activation and aggregation, would enhance endovascular lysis. Repeat angiography 48 hours following bivalirudin showed near total thrombus dissolution (middle row, right panel) with resolution of ECG abnormalities (lower ECG).

S N Doshi J D Marmur sagar.doshi@msnyuhealth.org
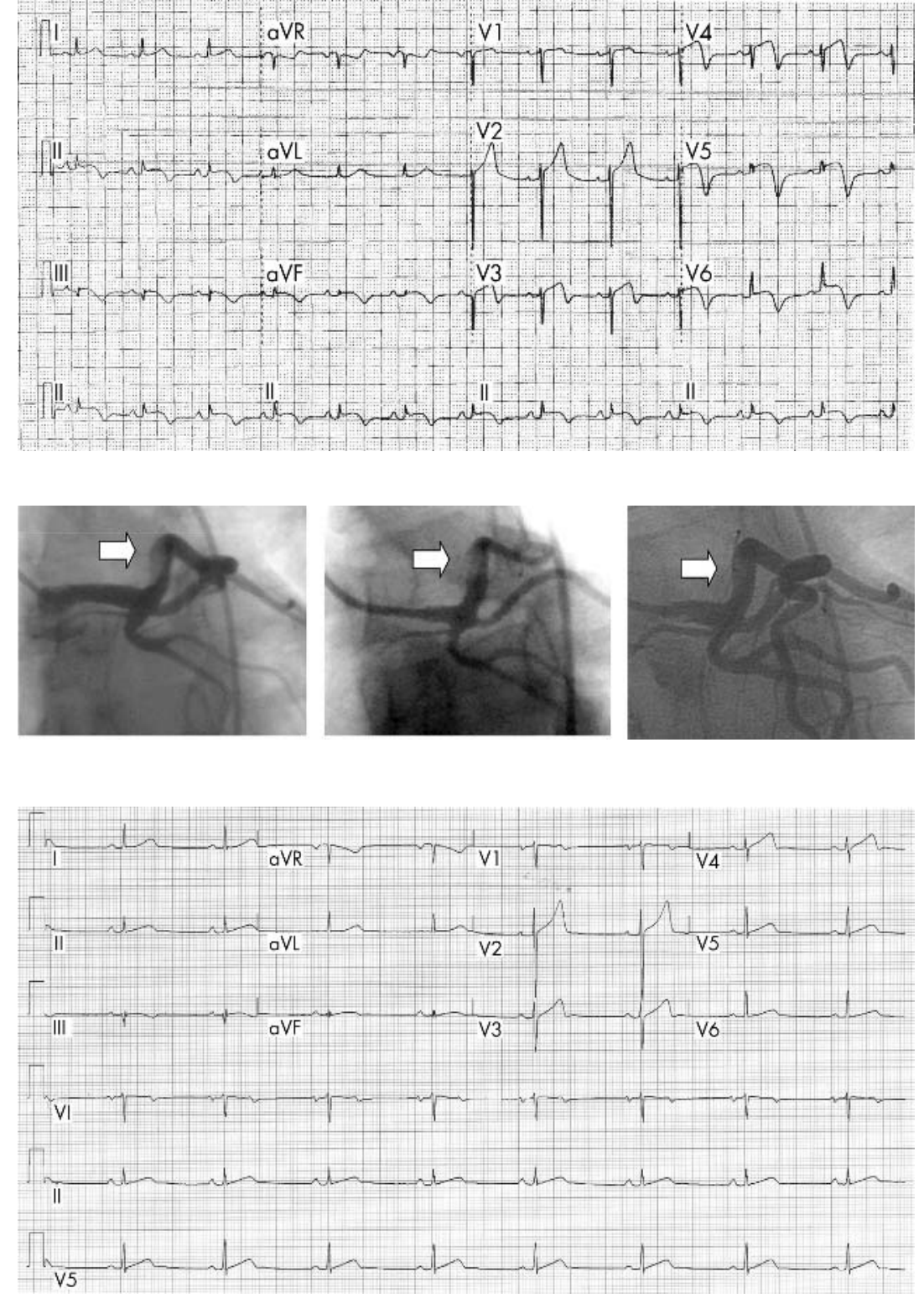